\title{
Exploration Into the Demand for Vocational Education System Construction
}

\author{
Yong Song, Liying Li*
}

\author{
Shanwei Polytechnic, China \\ *Corresponding author. Email: $826950941 @ q q . c o m$
}

\begin{abstract}
The construction of the education system for vocational and technical personnel is an important method to solve the problem of vocational and technical personnel training. In order to effectively cultivate professional and technical talents, it is necessary to solve the problem of improving academic qualifications during the growth of professional and technical talents. In addition, it is necessary to formulate a reasonable and effective development approach and management mechanism for the development of industrial and professional and technical personnel in order to fundamentally solve the problem of cultivating professional and technical personnel. 2019 G.F. (2019) No. 4 "National Vocational Education Reform Implementation Plan" put forward the system construction requirements for vocational talent training from the system. This provides the conditions for the promotion of vocational and technical talents, and can effectively solve the problem of student tiredness in vocational colleges and provide assistance for the development of vocational and technical talents.
\end{abstract}

Keywords: Vocational education system, talent cultivation, career development, degree

\section{A STUDY INTO THE PROBLEMS IN VOCATIONAL EDUCATION TALENT TRAINING}

With the deepening of the country's reform and opening up, industries and enterprises have achieved rapid development. Especially after the national strategy of "Made in China 2025" and supply-side reforms, the demand for vocational and technical personnel is increasing, the quality requirements for talents are constantly increasing, and the requirements for personnel training are increasing, which promotes the rapid development of higher vocational education in China. Many professional scholars have also researched the training of professional and technical personnel. Most scholars analyze and study the professional talent training required by enterprises based on their needs for talents. For example, Liu Jie and Zhang Haixia (2019) found three problems of enterprise talents through the investigation of textile enterprises: lack of practical ability of students, insufficient training of students 'comprehensive ability, and insufficient strengthening of students' professional ethics education [1]. The analysis of vocational education experts and scholars on vocational talent training mainly includes the following 12 aspects: education system, professional settings, talent training and job requirements, training goals and positioning, Curriculum system setting, teaching materials and supporting resources, personnel training management and evaluation system, teacher team building, "double teacher" teacher training, professional practice and training, teaching methods and methods, internationalization and informatization. In addition, the requirements for the reform of vocational education personnel training were put forward. After the state proposed supply-side structural reforms and "Made in China 2025", vocational personnel training to meet the needs of national reform began to emerge. Combined with the professional training of "Industry 4.0" abroad, the following are the contents and standards of reform and professional needs: professionalism, compound type, application type, high-skilled type, etc. For example: Wang Dongshan (2018) from eight aspects of talent training model positioning, training goals, specifications, cooperation mechanisms, national talent training plans, teaching materials, training and teacher training [2]; Wang Chao and Jin Rong (2019) analyzed seven issues in the training of accounting professionals from three aspects: the state, enterprises and vocational colleges [3]; Lu Jingquan et al. (2016) pointed out the direction and field of structural reform of the supply side of vocational education from six aspects [4]: constructing national vocational education system, improving professional structure of vocational colleges, constructing vocational education curriculum system, "double teacher type" teacher training, internationalization and informatization; and from the analysis of the effect of school-enterprise cooperation, they put forward the talent training requirements of enterprise perspective on the training of professional and technical talents. For example, Li Fei and Zhang Runhao (2018) proposed that the key to constructing a new mechanism of benign interaction between supply and demand lies in the "three strong" vocational student training with strong attitude, strong skills and strong applications [5]. It can be seen from the research results of current vocational 
education problems that although countermeasures are directly proposed based on the reasons, some of these countermeasures have high application value, which is of great help to improve vocational education, and a considerable part of In the practice of vocational education, it plays a role in improving the quality of personnel training. However, from the analysis of the professional education of experts and scholars, it can be seen that the improvement methods for vocational education problems seem to have entered a strange circle, problems occurred in personnel training for analysis and improvement, and new problems arise and reanalysis and improvement. With the development of economy and the upgrading of industry technology, similar problems have been plagued by the cultivation of professional and technical personnel. Therefore, it is necessary to consider how to make professional talents consciously improve their learning ability, vocational colleges actively strengthen their own training capabilities. Enterprises are willing to cultivate talents with masterpieces of higher vocational colleges, and continuously self-management and promotion of vocational colleges and professionals so as to solve the problem of vocational and technical personnel training. The most fundamental problem is that the vocational education system and system are not complete, and vocational and technical students do not see the space for increasing their academic qualifications. This has resulted in a disapproval of vocational education and an attitude of being tired of learning. Under the influence of students 'learning psychology, vocational college teachers are unable to better train students, and the resulting talent quality teacher-student problems, as well as the root cause of enterprises' unwillingness to cooperate. These have formed the problems of talent training itself in vocational education today. Of course, there are many other ways for students to progress to higher vocational colleges. Because they are not evaluated by vocational and technical personnel, and they are not measured against vocational and technical abilities, students and companies do not recognize academic qualifications. For example, Li Jianghong (2014) pointed out that foreign experience should be used to regulate higher vocational education, and establish a vocational education degree awarding system, just like ordinary higher education. In addition, a complete higher vocational system must be established, which can be divided into four levels: college, university, master, and doctoral degree, and different vocational and technical degrees should be awarded [6]. It is clearly pointed out that establishing a vocational education system is not only a solution to the problem of vocational education personnel training and development in China, but also a summary of the experience of vocational education management in developed countries.

\section{THE CONSTRUCTION OF VOCATIONAL EDUCATION SYSTEM CAN HELP TO SOLVE THE DEVELOPMENT PROBLEM OF VOCATIONAL STUDENTS}

On January 24, 2019, the Ministry of Education issued a national vocational education reform plan, and specifically proposed a vocational education reform implementation plan for the construction of a diploma system. The specific content is as follows: Improve the modern vocational education system that places equal emphasis on academic education and training, and unblock the channels for the growth of technical and skilled personnel. Develop a professional degree graduate training model that is oriented to vocational needs, with a focus on practical ability training, and a combination of production, teaching, and research, and strengthen the training of professional degree masters. Promote the transformation of qualified undergraduate colleges to application-oriented universities, and encourage qualified colleges and universities to offer applied technology-type majors or courses, and carry out a pilot of vocational education at the undergraduate level [7]. The national vocational education reform implementation plan specifically points out the inevitable law of talent training, proposes a systematic reform plan for the development of vocational education, and clarifies the important direction and content of vocational education reform. This is not only in line with the actual situation of vocational education in China, but also provides opportunities for the education and career development of vocational and technical personnel. After 40 years of reform and economic development, the development of vocational education in China has been greatly promoted. In recent years, vocational education has occupied half of the country's education. In the process of the rapid development of vocational education in our country, due to the increasing demand for talents in the industry, the enrolment scale of vocational education students has continued to expand, and the source and development of vocational education have continued to appear. There are the following aspects:

\subsection{Due to the Influence of Traditional Educational Thoughts, Vocational Education Is not Recognized in Society. The Educational Purpose of Confucius Was to Train "Officials" and "Gentlemen" [8]}

It is precisely because of the influence of traditional educational thoughts that vocational education is still inferior in society, and vocational education has certain pressures on student sources and development. Therefore, vocational education is required to improve the quality of talent training, improve students' professional ability and innovation ability, and improve the academic system required for the development of vocational students. Only 
in this way can we continuously improve the quality of vocational talents, improve the development space of vocational skills, and constantly change society's views on vocational education. The construction of the vocational education system solves the path for vocational students to advance to the next level, and improves the vocational education personnel training system, so that vocational students and ordinary students have different development platforms and similar education systems, which will better promote the development of vocational education.

\subsection{With the Expansion of the Enrolment} Scale, the Problem of Admission Structure Has Become Increasingly Prominent. In Terms of Higher Vocational Education, the Enrolment Structure Is Not Reasonable Enough, the Enrolment Is Culturally Oriented, the Examination Method Is Single, the Skill Examination Is Difficult, and the Enrolment Batch Is "Low-Quality First-Class" [9]

The enrolment of traditional vocational colleges is determined by the student's middle and college entrance examination results. Vocational colleges and universities usually conduct the examination structure with the general theory in the enrolment. This is not only detrimental to the enrolment of vocational colleges, but also fails to highlight vocational and technical capabilities. Even worse, vocational college admissions are usually arranged after ordinary admissions, and vocational college admissions are regarded as the minimum batch. Regarding the vocational education enrolment reform, although the structure of the student source has changed a lot, it is still a process mainly based on general examinations and supplemented by vocational skills examinations. In the process of constructing the vocational education system, the vocational education enrolment method required by the skills assessment is continuously highlighted, and the selection of vocational college students who highlight the skills requirements. With the improvement of the vocational education qualification system, it will be able to promote the reform of vocational admissions examinations and form selective examinations with vocational education characteristics.

\subsection{The Vocational Education System Is Not Smooth and the System Is Not Perfect, Which Limits the Training of Vocational Education Personnel and the Development of Vocational Education}

Restrictions on the progression of vocational and technical students, secondary technical colleges to junior colleges, undergraduates, and postgraduates, and junior colleges to undergraduates and graduates are restricted. Not only has it limited the upside for students, but it has also severely discouraged students from vocational colleges from learning. This makes students in vocational colleges unwilling to learn more, hoping to end their school studies as soon as possible and graduate to corporate personnel professional and technical work as soon as possible. In 2013, the proportion of graduates from secondary vocational schools in China was $14.5 \%$, the proportion of graduates from undergraduates was $25 \%$, and only the proportion of graduates from undergraduates was $5 \%$, which became a bottleneck for further studies [10]. The problem of junior colleges and higher education is embarrassing the development of vocational education, which directly prevents the vocational school students from improving their academic qualifications, and the lack of applied undergraduate colleges has aggravated the room for higher vocational students' academic qualifications, and indirectly caused vocational college students' classroom tiredness learn. Liu Hongyin, Yang Yaofang, and Han Xiaoqiang (2011) believe that: in short, social prejudice, expected return rates close to opportunity costs, and poor access to education are the main reasons for the difficulty of recruiting rural secondary vocational students [11]. From the analysis of the current situation of enrolment in rural secondary vocational schools, one of the main reasons is the proportion of junior college graduates, which is caused by the incompleteness of the current vocational education system.

\section{THE CONSTRUCTION OF VOCATIONAL EDUCATION SYSTEM MEETS THE REQUIREMENTS OF VOCATIONAL EDUCATION AND PROFESSIONAL TALENT DEVELOPMENT}

In fact, there are three problems in the development of students in vocational colleges. As long as the vocational and technical student system is perfect, so that students in vocational colleges have a smooth ascent channel, they will be able to promote their own efforts and let vocational college students seriously learn professional knowledge and expertise. Through the improvement of professional knowledge and professional skills, we can obtain higher education opportunities, realize the academic advantages of students in career development, change the current situation of vocational education students' weariness, and form a new scene of conscious learning for vocational students. After the students' professional knowledge and skills are improved, they can show better innovation and development capabilities. Vocational education will inevitably be recognized by enterprises and society, promote the development of vocational education teachers, and form a good vocational education talent training system. The national vocational education reform program highlights the vocational education qualification system and skills requirements, meets the development needs of 
students in vocational education reform, and is an effective reform program to solve the problems of current vocational and technical education. This is reflected in the following aspects:

\subsection{The Construction of the Vocational Education System Reflects the Time Requirements for the Growth of Technical Talents}

The training of technical talents requires a specified time course, and the transition from novice to high-skilled compound talents requires a long career growth process. And in this long career growth process, professional and technical personnel are required to continuously learn professional knowledge and practice professional operation and practical skills according to the needs of technological development. With the proficiency of operation technology in professional development, it is necessary to continuously master a large amount of professional technical theoretical knowledge, and through in-depth understanding of professional technical knowledge, to achieve continuous improvement of technical operations and technical operations. The technical expertise process cannot use simple systems and specifications to reduce the training time. It can only be adjusted appropriately to speed up the process of some professional studies according to the characteristics of the technology and individual circumstances. Xiao Yong (2018) believes that, in general, the development of high-skilled talents in power grid companies has to go through the adaptation, stable, mature, development, and differentiation periods. In addition, he believes that every 5 years is a stage, and the adaptation period: generally, refers to the period of 1-5 years in the work, the junior stage; the development period: generally, refers to the period of more than 10 years, the senior stage; the mature period, generally refers to working for more than 15 years and reached the stage of technicians and senior technicians [12]. Of course, in the process of professional growth, professional and technical personnel must closely associate their vocational skills with production and work, improve their skills at work, and continuously innovate in their skills. Through the close cooperation of the two, continuous improvement in skills is achieved, and work ability is continuously improved in the progress of skills. As an experience, skills must be mastered and improved step by step in the practice of production and work. Its improvement is gradual and cumulative [13]. Work skills must be improved in actual work practice, and step-by-step and progressively improved in the work process. Leaving the job cannot help to improve vocational skills, which is also the fundamental reason for the combination of work and learning to cultivate professional talents.

\subsection{The Construction of the Vocational Education System Reflects the Requirements for Improving the Professional Education of Vocational and Technical Personnel}

Professional and technical personnel need to develop in a reasonable and smooth institutional environment. According to the continuous improvement of vocational skills, it must be continuously recognized in the government, society and enterprises, and it should continue to reflect its due technical and professional value. At present, vocational and technical personnel can only be recognized by enterprises after their own skills are upgraded. The national and social recognition is not high, and it cannot be compared with the status obtained by other personnel's similar efforts. This is exactly the problem of professional development of professional and technical personnel. According to statistical analysis by industry insiders, it takes 8 to 10 years to train a senior worker in China, 12 years to train technicians, and 15 years to train senior technicians [14]. Through more than ten years of enterprise skills work, he has achieved the ability of more than one technician in professional skills. Because the national certificate system cannot be comprehensive, and cannot be used to represent its applied skills, and academic qualifications have become a feasible way to improve the skills of vocational and technical personnel. The national vocational education reform plan proposes: to develop a professional degree postgraduate training model that is oriented to vocational needs, with emphasis on practical ability training, and a combination of production, teaching, and research, and strengthen the training of professional masters [7]. Employ the academic system to reflect the abilities of professional and technical personnel, and solve the problem of the development of professional and technical personnel from the management of professional and technical personnel. This also helps professional and technical personnel to continuously obtain higher education and gain recognition from the country and society in the process of professional development.

\subsection{The Construction of the Vocational Education System Has Laid a Foundation for Improving the Welfare of Vocational and Technical Personnel}

Wage distribution is an important manifestation of paying for labor, and a fair and just wage distribution system is an important method for resolving talent conflicts. Due to the imperfect system of professional and technical titles and the professionalism of professional and technical standards, there is no way to measure it with a uniform salary distribution standard. Therefore, education is still the best method for current application. The higher the education level, the higher the salary; the longer the working age, the higher the salary, which is still the standard commonly used by many foreign-funded 
enterprises. Many countries have a system of salary distribution based on academic qualifications. In the developing country, the income of those who completed primary education in the Philippines in 1981 was 1.23 times that of those who did not complete primary education. The income of those who completed secondary education did not. 2.11 times; and the income of those who completed higher education was 3.9 times that of those who did not complete primary education [15]. (Ma Fanwen 2002) There is also a similar analysis: different education levels cause differences in wage income, which is not unique to a particular country; education levels have a greater impact on individual wage income. In general, the higher the education level, the higher the corresponding wage income, and the two have a higher positive correlation. The higher the level of education, the higher the relative employment rate, which can reduce the threat of unemployment and ensure the receipt of wage income [16]. Judging from China's situation, education and wage income also show positive correlation characteristics. Moreover, some scholars have concluded that the education level is closely related to labor productivity and wage income through related analysis. [16, 17] These research results further illustrate that education is not only the basis for salary distribution, but also the basis for achieving high employment rates and improving labor productivity. Of course, in similar situations, many companies have conducted in-depth research, as well as deeper research. For example, in the selection of electronics engineers in an electronics company in Dongguan, high-skilled positions such as research and development will give priority to hiring graduate students and undergraduate graduates from key universities with strong electronics majors; In the application technology research and development, undergraduate graduates majoring in electronics majors are selected. For basic operational skills, high-school, secondary and tertiary graduates are selected for cultivation. This shows that academic qualifications are also an important basis for companies to choose positions for technical personnel.

\subsection{The Construction of Vocational Education System Should Highlight the Quality Requirements for Talent Training}

The reason for the mismatch in education is that the labor force has been "over-educated" [18]. This is a problem of marketization of higher education, and the problem of mismatch in education qualifications brought about by marketization of higher education. It is necessary to strengthen the construction of vocational and technical teachers' colleges, support high-level schools and large and medium-sized enterprises to jointly build dual-teacher training bases, and establish a mechanism for joint training of dual-teacher teachers by institutions of higher learning and industries. Moreover, it is necessary to effectively promote the vocational college teachers to regularly practice in enterprises and continuously improve their practical teaching capabilities [19]. Before the reform of vocational education, the state put forward corresponding requirements for the construction of professional teams. The construction of the vocational education system must also ensure quality assurance, ensure that high-quality technical personnel have opportunities for further studies, and ensure that vocational students with advanced studies meet the quality requirements. Establish a vocational education quality evaluation system based on learners professional ethics, technical skills and employment quality, as well as the integration of production and education, and the level of school-enterprise cooperation [7]. Establishing a vocational quality evaluation system to accompany the construction of a vocational education system, to ensure the quality management of the vocational education system, and to build a vocational education qualification system to provide vocational college students with room for improvement. It is not necessary to open up further education channels for all vocational college students. Only capable and qualified learning can be provided with opportunities and space for further studies, to ensure the quality of vocational colleges in terms of talent training and qualifications, and to solve the "over-education" problem of mismatched education. In addition, in order to ensure the quality of personnel training in the vocational education reform process, the national vocational education reform plan clearly states that starting from 2020, higher vocational colleges will not recruit teachers among fresh graduates. And promote the two-way flow of corporate technical talents and professional teachers in vocational colleges, mutual employment, school-enterprise cooperation and other methods. In this way, it can promote the direction of enterprise demand for vocational education talent cultivation, solve the current problem of mismatch between academic qualifications and abilities, promote the vocational and technical talent cultivation required by enterprises, and lay the foundation for solving the current problem of excessive labor education in society.

\section{CONCLUSION}

From the construction of the vocational education system, the article analyzes the implementation plan of the national vocational education reform to solve the education problem in the training of vocational education talents. In addition, this article analyzes the enthusiasm of vocational students that may be brought about by the opening of further education channels, and the construction of vocational education system provides opportunities for the development of vocational students, and solves the current problems of quality of transitional education. Of course, the construction and management of the vocational education system has many advantages for the development of vocational education. It needs to be continuously summarized in the specific implementation process, and the reform plan should be used to improve the problems that may arise during the reform. With regard to current vocational education issues, the construction of a 
vocational education system, especially a degree system that meets the development needs of vocational students, can solve many problems of current vocational education. The national vocational education reform implementation plan puts forward comprehensive reform requirements for the construction of the vocational education system. There is still a lot of content that needs to be studied during the vocational education reform process and continuously reformed and practiced in the development of vocational education. In order to solve the current problems of vocational education and improve the quality of vocational and technical personnel training, the national vocational education reform plan should be speeded up, and the vocational education system needed for vocational education development should be established and improved as soon as possible.

\section{ACKNOWLEDGMENT}

Guangdong Higher Vocational Education Research Association 2019 Project "Research on the Construction of Vocational Education System with Guangdong Characteristics" (Subject No. GDGZ19Y161).

\section{REFERENCES}

[1] Liu Jie, Zhang Haixia, Talent Cultivation Countermeasures Based on Talent Demand Investigation of Textile Enterprises [J]. Light Industry \& Technology 2019.48 (04) P92-94

[2] Wang Dongshan Research on the Training Model of Higher Vocational Compound Talents Facing Enterprise Demands — Taking the Training of Furniture Marketing Talents as an Example [J]. Vocational Technology 2018,07

[3] Wang Chao, Jin Rong Thoughts on the Cultivation of Accounting Professional Talents in Higher Vocational Education Based on the Perspective of Enterprise Demand [J]. China Vocational and Technical Education 2019.01 P55-P60

[4] Lv Jingquan, Ma Yan, Yang Yan, Liu En, Monograph on Supply-side Structural Reform in Vocational Education [J]. Jiangsu Education 2006.05 P20-P23

[5] Li Fei, Zhang Runhao, Higher Vocational Supply-side Structural Reform Based on the Quality Requirements of Enterprise Employees in the "Industry 4.0" Era [J]. Education and Occupation 2018, (07), 44-47
[6] Li Jianghong. Thoughts on the Problem of Undergraduate Progression of Higher Vocational Students in China from the Perspective of Career Planning [J]. Education and Occupation 2014, (06), $39-40$

[7] State Department. National Vocational Education Reform Implementation Plan [N] Guofa [2019] No. 4 2019.01.24

[8] Wang Junqi. Talking about Chinese Traditional Education Thought and Modern Vocational Education [J]. SME Management and Science \& Technology (First Issue) 2016.09) P156-157

[9] Jiang Lijun, Bian Xincan, Zhuo Yiyuan. Some Thoughts on the Enrolment of Higher Vocational Education Examinations - From the Perspective of the New College Entrance Examination Reform [J] .China Higher Education Research, 2016.07 P97-101.

[10] Wang Fei, Li Zhihong, Survey and Analysis of the Demand for Higher Vocational College Students in China [J]. China Vocational and Technical Education 2015.04 P 69-73 + 96

[11] Liu Hongyin, Yang Yaofang, Han Xiaoqiang, Causes and Countermeasures of the Difficulties in Enrolling Rural Secondary Vocational Education in China in the New Era [J]. Vocational Education Forum 2011.04

[12] Xiao Yong. Formulate training plans according to the growth law of high-skilled talents in power companies [J]. China Electric Power Education 2018.06 P18-19

[13] Zou Xinyao. Research on the cultivation of high-skilled talents based on the law of talent growth [J]. Journal of Guangdong Agricultural and Commercial Vocational College 2011.05

[14] Han Wei, Zhang Jiliang, Perspective on the Growth Law of High-skilled Talents [J] Chinese Adult Education, 2007.10 P83-84.

[15] Lai Desheng. Education and Income Distribution [M]. Beijing Normal University Press, 1998.

[16] Ma Fanwen. A Comparison of the Correlation between Educational Level and Wage Income in China and Foreign Countries [J]. Journal of Guangzhou University 2002.05 
[17] Translated by Min Weifang, et al. International Encyclopedia of Educational Economics [M]. Higher Education Press, 2000, p 185.

[18] Chen Hao, Chen Jianwei. Has the rise in industry wages really caused mismatches in academic qualifications? - Retesting based on the revised method for measuring mismatches in academic qualifications [J]. Finance and Economics Research 2014.40 (11) 121-132

[19] CPC Central Committee, State Council, Opinions on Deepening the Reform and Construction of Teachers in the New Era Opinions of the Central Committee of the Communist Party of China and the State Council on Deepening the Reform and Construction of Teachers in the New Era [N] 2018. 01. 20. 